\title{
METHOD FOR HARVESTING SOLAR ENERGY
}

Hussain Bassi,

King Abdulaziz University,

Faculty of Engineering,

Department of Electrical

Engineering,

Jeddah, Saudi Arabia

Key words: solar PV system, solar cooling, photovoltaic, energy harvesting, solar energy

\section{Cite article:}

Hussain B. [2021]. Method for harvesting solar energy. Journal of Applied Engineering Science, 19(2) 504 - 514. DOI:10.5937/jaes0-28761

Online aceess of full paper is available at: www.engineeringscience.rs/browse-issues 


\title{
METHOD FOR HARVESTING SOLAR ENERGY
}

\author{
Hussain Bassi* \\ King Abdulaziz University, Faculty of Engineering, Department of Electrical Engineering, Jeddah, Saudi Arabia
}

The cooling of the surface of the solar photovoltaic (PV) system is a major operative factor in achieving greater efficiency. Correct cooling can improve electrical efficiency and reduce cell degradation rates over time. This results in increasing the life of the solar PV modules. In industrial and domestic utilization, the cooling system is used for the removal of excess heat. This paper presents a new method for cooling systems for solar PV which results in the improvement in the collection of the solar insolation. The additional feature of the method has been the tracking of sunlight for efficient power generation. Further, the extra heat can be utilized for other purposes including heating and power generation through thermal means. The concept of the proposed system has been explained in detail with the pictorial representation. Also, for the validation of the improved performance of the proposed system, a detailed comparison with the conventional methods have been provided for five different cities of Saudi Arabia and an improvement of twice collection of insolation has been estimated compare to the conventional systems. The proposed system shows improved performance for all operating conditions.

Key words: solar PV system, solar cooling, photovoltaic, energy harvesting, solar energy

\section{INTRODUCTION}

One of the popular and widely used renewable energy technologies is the use of PV structures that transform sunbeams into a usable form of electricity [1,2]. This type of pollutant-free renewable energy technology reduces the operational cost, offers low maintenance, have good impact on global warming related problems, and high power density over other non-conventional or renewable energy sources, highlighting the benefits of solar PV systems [3, 4]. Apart from the several advantages of PV technology, this energy conversion system has certain general problems, including hail, dust deposition and surface operating temperature, which can adversely affect the conversion system's efficiency [5]. The most common natural factors influencing a PV module's surface temperature [6] include exogenic climate parameters such as wind speed, ambient temperature, relative humidity, accumulated dust and solar radiation. Every $1^{\circ} \mathrm{C}$ surface temperature increase in the PV module causes an efficiency decrease of 0.4 $0.5 \%[7-9]$. Thus, not all the solar energy absorbed by the photovoltaic cells is converted into electrical energy due to the increase in temperature. In order to comply with the energy conservation law, the remaining solar energy is converted into heat. The effects of this wasteful heat reduce the overall conversion efficiency. In order to make renewable energy technology a viable solution, efficiency improvements in solar energy conversion systems must be made. In order to be a viable solution, different ways to resolve this temperature problem have to be found, leading to an increase in total conversion efficiency.

In [10], the authors presented an overview of different methods for photovoltaic cell cooling. However, when looking closely, it can be seen that the paper focused only on examining the passive, forced air and forced liquid convection cooling methods used by various solar con- centration systems. In [11], two colling methods based on close loop water cooling and active air cllong has been discussed in detail and experimentaly validated. Further in [12], the various methods for the positioning of the solar PV cells has been discussed.

Very few authors have attempted to develop and undertake a comprehensive review of various technologies used to cool the operating surface of solar panels in order to increase the overall efficiency of solar conversion. The authors of this paper [13] talked briefly about various cooling technologies for solar panels. Only a few technologies were implemented while the main focus of the paper was on the testing and performance of a developed GCC panel cooling system. The authors presented an overview of different methods that can be used to cool photovoltaic cells in reference [13]. However, it can be seen, when closely examined, that the paper focuses only on the examination of passive, forced air and liquid forced convection cooling techniques applied to various solar concentrate systems. Although solar energy plants have been around for many years, their generation of electricity is costly compared to alternative generation methods such as coal or natural gas. This problem has been compounded by the costly shortage of solar-grade silicon. One solution to offset high production costs is to improve photovoltaic efficiency by reducing the amount of material used and keeping the sunlight on the photovoltaic panels during the day. Current methods include concentrating sunlight in a smaller area of the solar cell and rotating the solar panel. With regard to the former solution, reducing the material used for building the solar cell saves money, but concentrators can use complex optical systems that require costly lenses and curved mirrors. The complete panel assembly can also lead to higher operating costs because of the need to move a heavy structure (both the complete solar cell assembly and the smaller solar cell, with a large concen- 
trator assembly). A solution is required which can monitor the movement of the sun to direct sunlight to the panel and can therefore improve efficiency while retaining low operating costs. In addition, a solution that protects and cleanses the solar cell surface can mitigate performance degradation from deposited surface waste. In this paper, a new concept of cooling of solar PV is discussed and explained in the following section.

\section{PROPOSED SYSTEM}

Fig. 1 shows the proposed solution for the cooling system with the tracking of sunlight. The PV system contains a $\mathrm{PV}$ cell that has at least one mirror attached to the PV cell. As shown in Fig. 1, two mirrors are included in the PV system. Each mirror is attached with a DC motor which is used for rotating the mirrors. The PV cell is attached to a heat exchanger, and fluid is circulated via a fluid pump and into a heat exchanger to cool down the fluid. Different components of the proposed system are described below: The PV cell contains a sun tracking device that is configured to determine the angle and intensity of the incidence of the sunlight. The PV cell has a bottom surface configured to dispel heat produced by sunlight and photovoltaic cell operation. The mirrors may be a panel of reflective material that reflects solar radiation on the photovoltaic cell. The reflective material can reflect wavelengths of ultraviolet, visible light and infrared radiation in the electromagnetic spectrum. The reflection of wavelengths of 100 $\mathrm{nm}$ to $3000 \mathrm{~nm}$ can, for example, be specular, preferably $150 \mathrm{~nm}$ to $2500 \mathrm{~nm}$, or $250 \mathrm{~nm}$ to $2000 \mathrm{~nm}$. The mirrors are arranged above the top surface of the PV cell and are so large that the mirrors cover all or almost all of the surface of the PV cell when the mirrors rotate and lay flat. As shown in Fig. 1, each of the two mirrors is around onehalf of the PV cell, and the mirrors are disposed along the long edges of the PV cell. In an alternative way, the mirrors can be arranged along the short edges of the PV cell, with less elongated, square shapes and each covering approximately one half the PV cell. In another version, the mirrors can be configured for further reflective panels to extend the reflective area. Fig. 2 (a) - (c) shows a spreadable mirror in one or more aspects of the subject matter disclosed. Via the hydraulic actuator and the DC motor, the mirrors are connected to the PV cell. The hydraulic actuator is fixed at a predetermined position on the side, for example, of the PV cell panel, at the first end. The DC motor is attached on the second end of the hydraulic actuator. The mirrors are attached to the center of the DC motor on the edge of the mirrors so that the DC motor can rotate the mirrors clockwise or counterclockwise, or mix the two directions in which the rotating switch after a predetermined period of time. The program for the rotational speed at different rotation per minute (RPM), i.e. less than 1 RPM, 100 RPM or 5000 RPM. The hydraulic actuator can be set up to be extended or retracted by a quantity of fluid received or pumped out by the pump. This extension or retraction can increase or decrease the distance from the top of the PV cell from the mirrors. The mirror can be connected via the hydraulic actuator and DC motor to the $P V$ cell on each end. In an alternative way, the mirrors can be connected to the PV cell by a hydraulic actuator and a DC motor and connected to the opposite end through a hydraulic actuator without a DC motor.

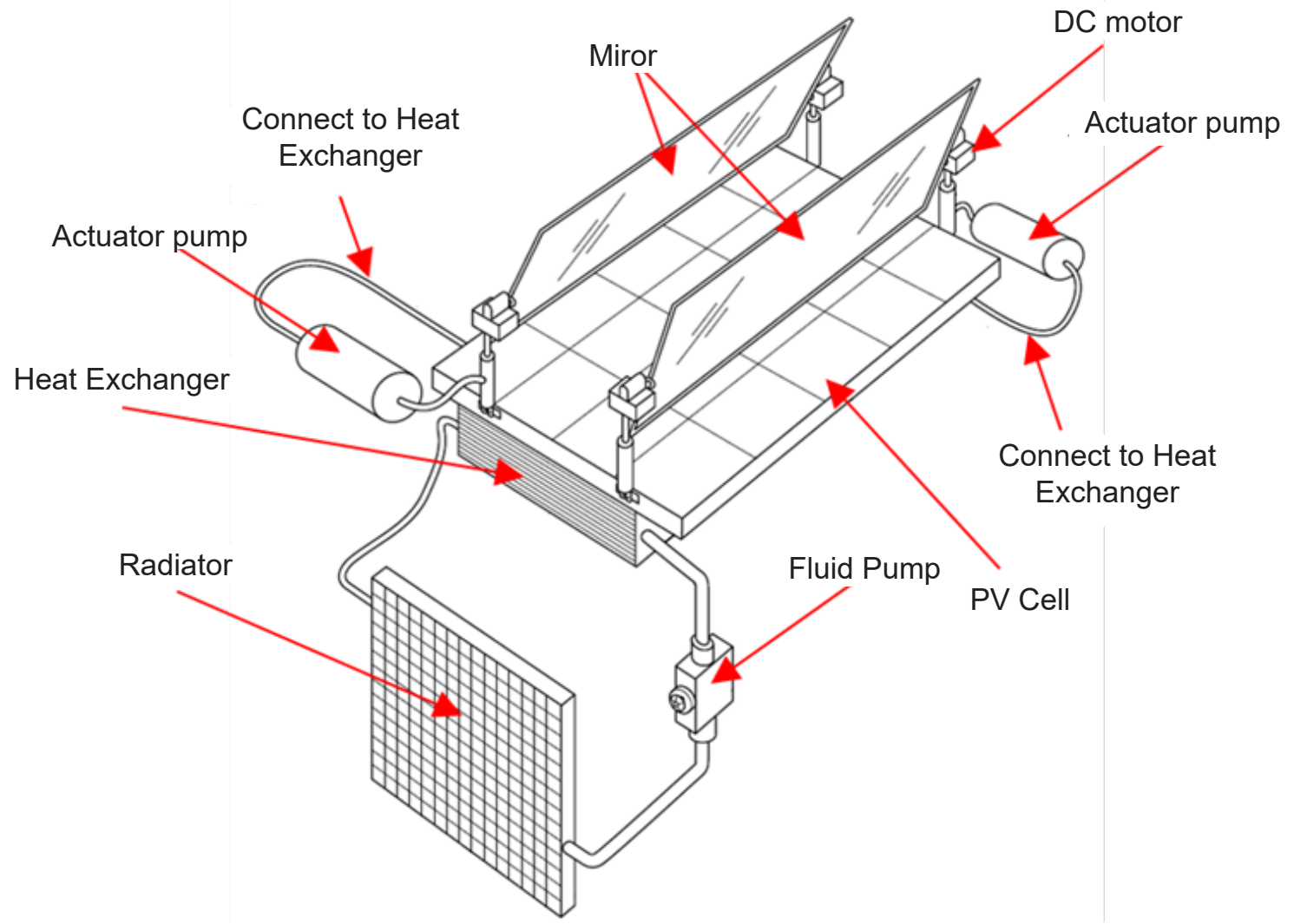

Figure 1: Proposed system[14] 

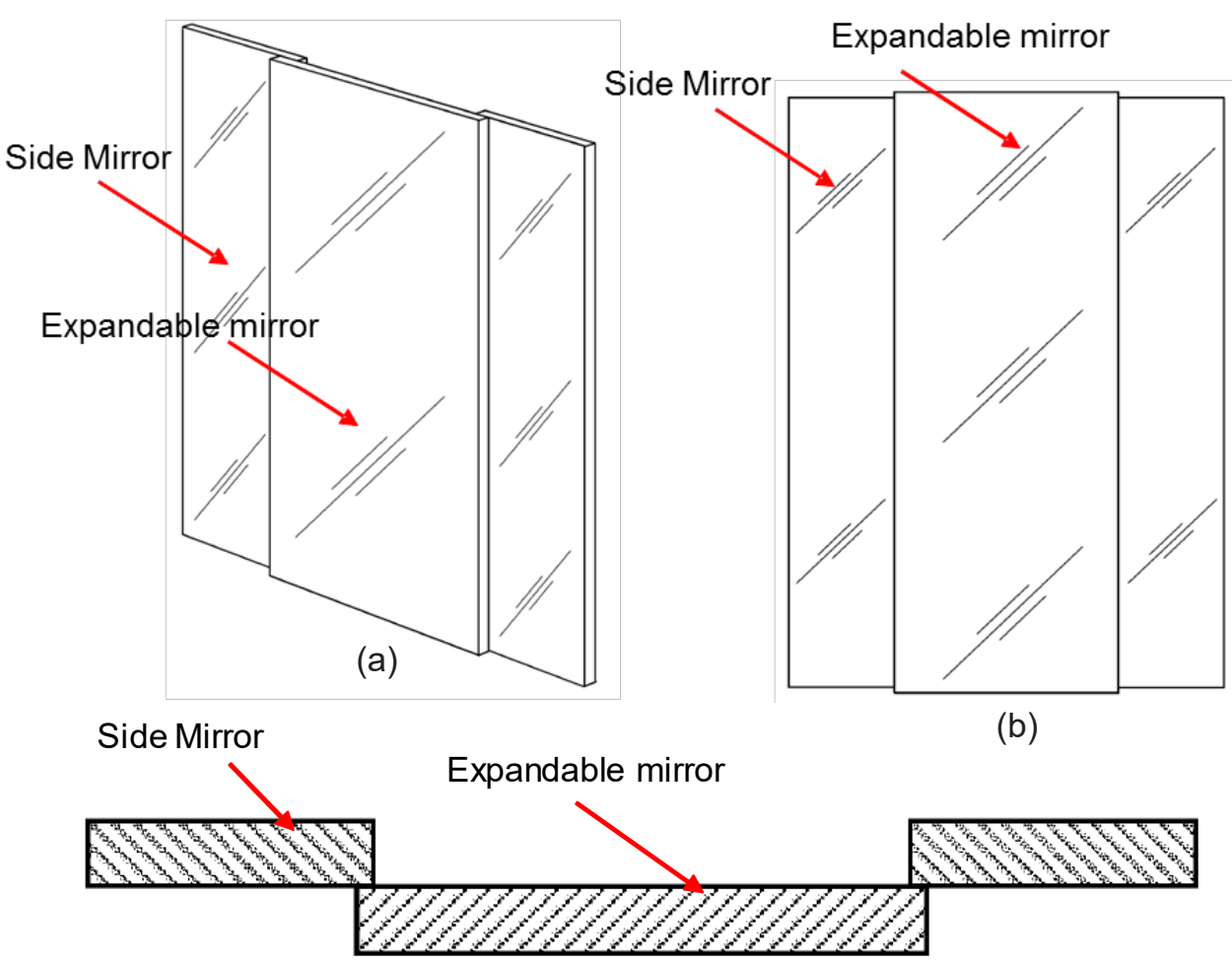

(c)

Figure 2: Mirrors arrangements

A heat exchanger is also connected to the actuator pump. Through the actuator pump, fluid from the heat exchanger can be pumped into the hydraulic actuator to extend the hydraulic actuator and to increase the mirror height. Fluid from the heat exchanger can also be removed from the hydraulic actuator by means of the actuator pump to reduce the mirror height. The incorporation of the actuator pump into the heat exchanger increases the cooling capacity thanks to the increased amount of fluid in the alternator. The sun moves through the sunrise from the horizon to the summit and back to the horizon at sunset. The sunlight includes two main components, the direct beam that carries most of the solar energy and the sun, which carries the rest. The direct beam sunlight contributes energy with the cosine of the angle between the incoming light and the PV cell. If the PV cell is oriented on a surface, for example a roof where the photovoltaic cell plane is parallel or nearly parallel with the ground, the PV cell will not receive so much direct beam sunlight at sunrise and sunset as if the sun is positioned overhead. As shown in Fig. 3 (b), The sun-tracking device can be configured to determine the sun 's position and instructed the DC motor to rotate the mirrors to reflect the direct beam sunlight in the PV cell based upon one or more aspects of the disclosed object. The mirrors can, for instance, be rotated to reflect sunlight on the pv cell in which the reflected rays are perpendicular to the top surface of the pv cell. During the sun's movement from the horizon to the summit, a shadow behind the mirrors can shape and result in a net decrease in the PM cell's energy production compared to the sunlight on the photovoltaic cell. Fig. 4 (a) illustrates an example to reduce the shadow of the mirrors in one or more of the aspects of the subject matter disclosed. At a default sun position, the mirrors may rotate to the direction where the shade of the mirrors' thickness is minimized; for example, the mirrors may rotate so that the mirrors' plane is parallel to the direction of direct sunlight from the beam. As shown

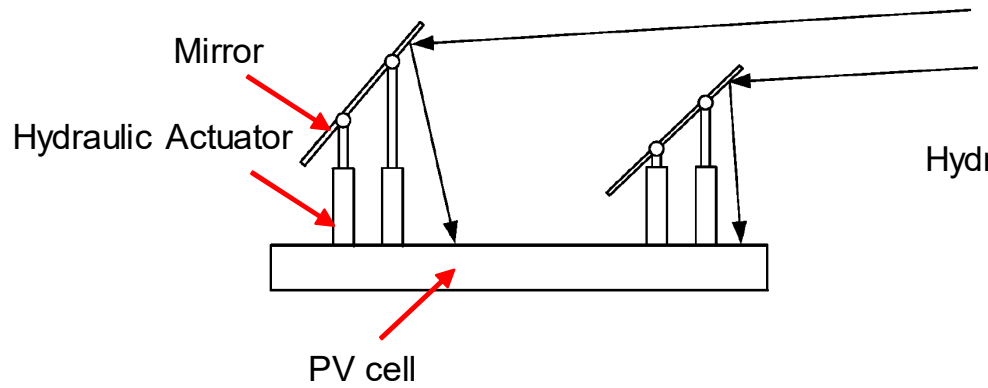

(a)

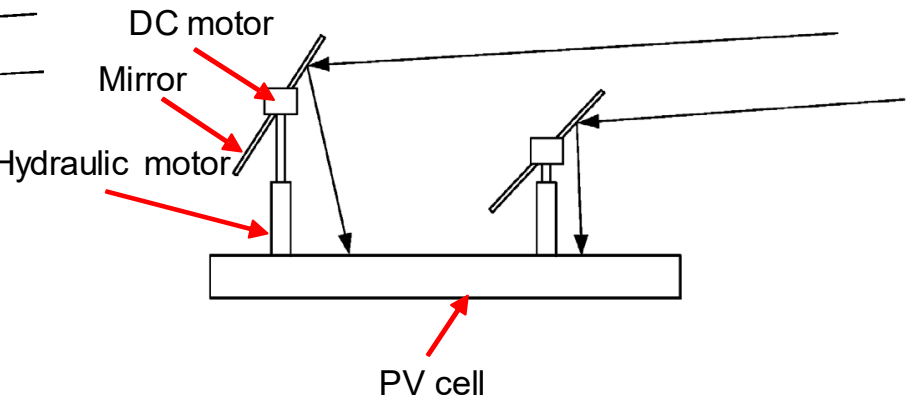

(b)

Figure 3: Arrangement of hydraulic system 
in the Fig. 4 (b) In accordance with one or more aspects of the subject disclosed, at sunset or determination in the PV cell that the weather is not optimal for power generation, if energy generation does not exceed a pre-determined threshold for example, the mirrors could be rotated parallel to the top surface area of the PV cell and laid flat to protect the surface from debris. The mirrors can be arranged over the top surface and moved closer to the top surface until the mirrors are in contact with the top surface of the PV cell.

The PV cell can also be configured to detect the presence on the PV cell surface of accumulated debris such as water, sand, ice and other external materials. For example, the PV cell can determine its power generation based on sunlight received, e.g. via one or more sensors and can trigger a cleaning process with the predetermined threshold of a declining power generation. Fig. 4 (c) illustrates an example of the cleaning procedure orientation in accordance with one or more aspects of the subject matter disclosed. This cleaning process may involve repositioning the mirrors at a predetermined distance from the top of the PV cell and turning the mirrors at high speeds, e.g. 100 RPM or 5,000 RPM, to produce turbulent airflow. The resulting turbulent air can clear the PV cell surface and restore operational efficiency, such as water, sand, ice and other foreign materials. Thus, optimum design of the mirror can be determined wherein the structural integrity of the mirrors is preserved for cleaning events where the mirror has high deformity forces, such as a centripetal force and the shadow caused by the splitting thickness of the mirrors can be reduced as thin as possible.

Fig. 4 (d) illustrates another example of a cleaning procedure guidance in one or more aspects of the subject-matter disclosed. The mirrors can clean the surface of the pv cell in an alternating movement from and to the surface of the pv cell. The mirror plane can be rotated almost in parallel to the plane of the PV cell, while the hydraulic actuator can be configured to increase or decrease the mirror distance from the top surface of the PV cell. For instance, the PV cell is nearly parallel to the ground, and the mirrors can start at a height just above the surface of waste, for example, ten centimeters above the surface, and the hydraulic actuator can raise the mirror height. The hydraulic actuator can decline the mirror height after reaching a predetermined height. The height increase and decrease motion can cause a pressure difference between the two sides of the mirror.

\section{PERFORMANCE ANALYSIS}

\section{Proposed system}

As discussed in the previous section, Fig. 5 shows the schematic diagram of the proposed technique for solar PV harvesting. The two mirrors $A$ and $B$ tracks the solar irradiation and reflects it perpendicular to the solar PV to get maximum energy. Due to the presence of the mirror, a shadow is created which is also shown in Fig. 5.

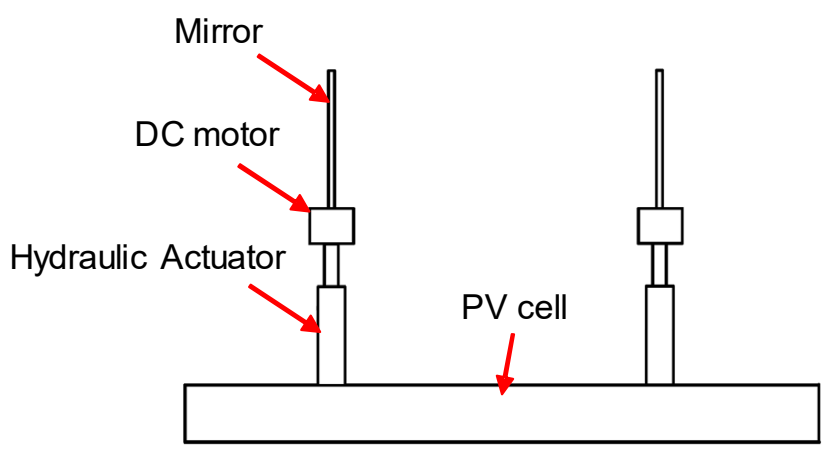

(a)

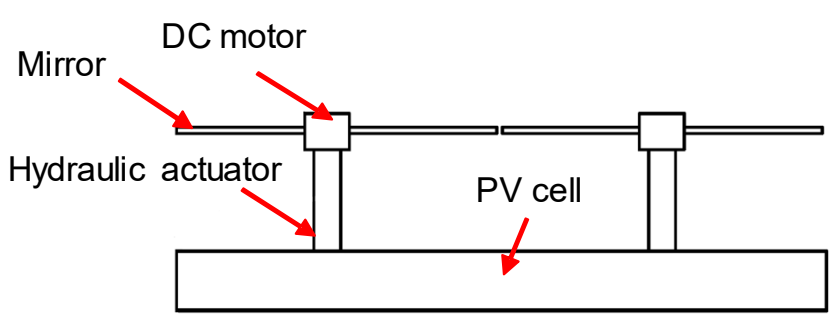

(b)

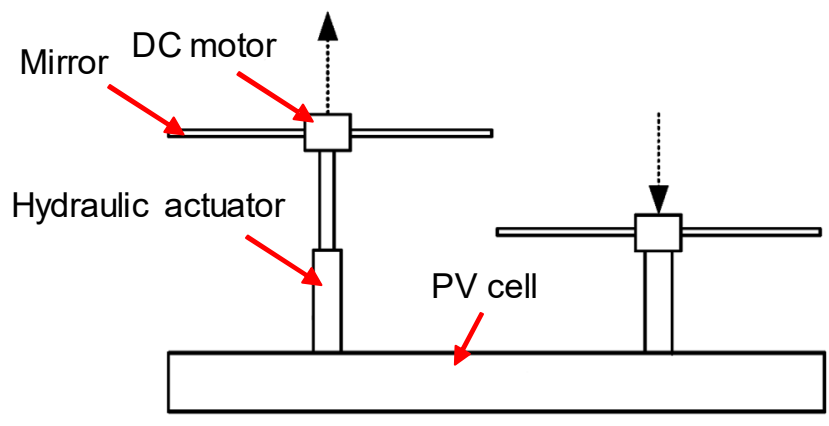

(c)

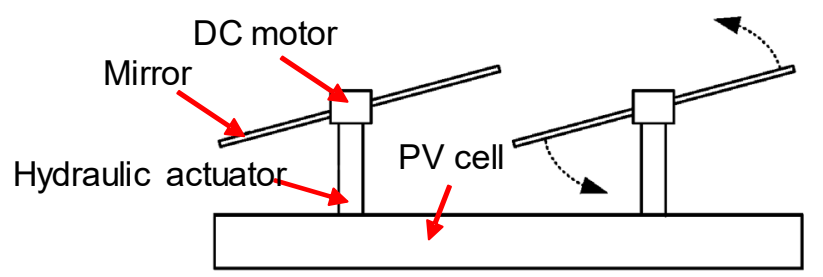

(d)

Figure 4: Different position of mirrors

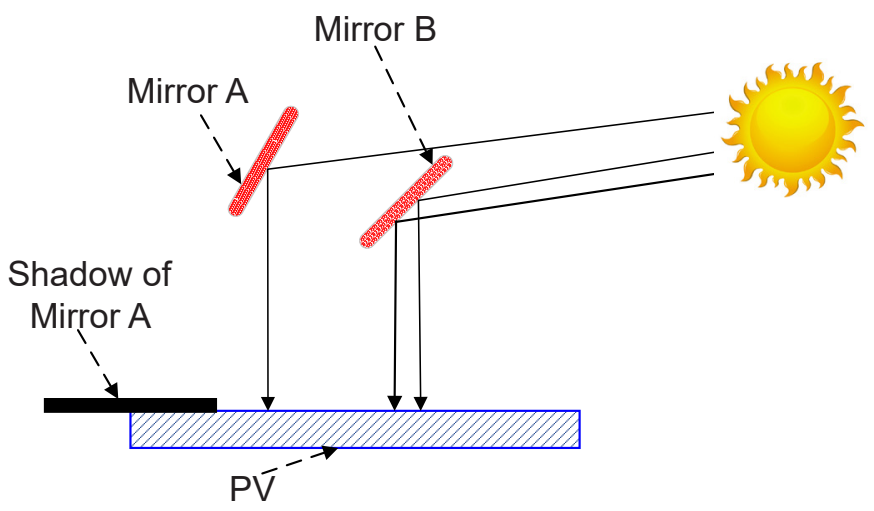

Figure 5: Schematic diagram of the proposed technique 
For the different formulation of the proposed technique,

Fig. 6 provides detailed information, where

$\mathrm{m}=$ mirror length $(\mathrm{m})$

$\mathrm{C}=$ length of the solar collector $(\mathrm{m})$

$\theta=$ irradiance angle on mirror (radian)

$\beta=$ irradiance angle of solar (radian)

Based on Fig. 5, different lengths can be calculated as

$x_{1}^{\prime \prime}=X-\frac{1}{2} m \cos \theta$

$X_{1}^{\prime}=\frac{Y_{1}}{\tan \beta}$

$x_{1}=\left\{\begin{array}{l}c-\left(x_{1}^{\prime}+x_{1}^{\prime \prime}\right) ;+v e \\ 0 \quad ;-v e\end{array}\right.$

$X_{2}^{\prime \prime}=X+\frac{1}{2} \cos \theta$

$X_{2}^{\prime}=\frac{Y_{2}}{\tan \beta}$

$x_{2}=\left\{\begin{array}{l}c-\left(x_{2}^{\prime}+x_{2}^{\prime \prime}\right) ;+v e \\ 0 \quad ;-v e\end{array}\right.$

$Y_{1}=Y+\frac{1}{2} m \sin \theta$

$Y_{2}=Y-\frac{1}{2} m \sin \theta$

The shaded ratio (SR) can be calculated as

$S R=\frac{x_{2}-x_{1}}{C}$

Therefore, the light ratio (LR) can be calculated as

$L R=1-S R$

The mirror angle $\theta$ based on the sun angle can be calculated as

$\theta=\frac{\beta+90}{2}$

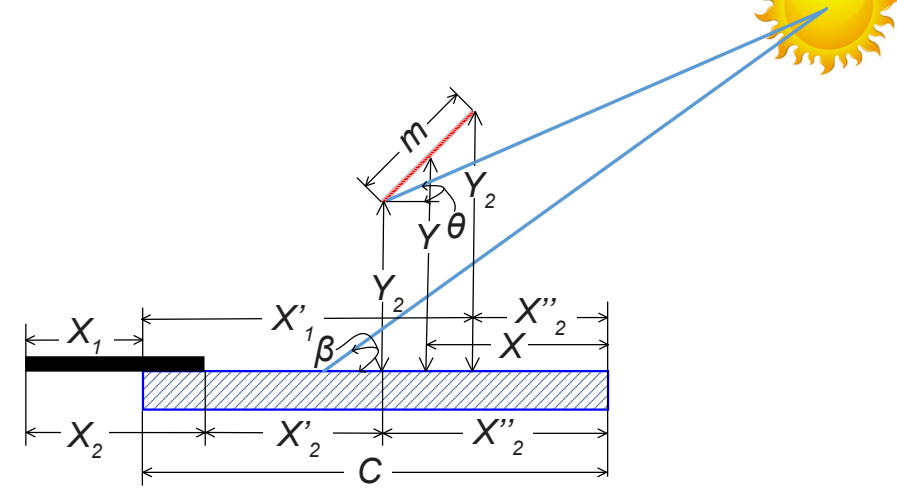

Figure 6: Analysis of the proposed technique with one mirror

\section{Fixed system}

The main performance parameter for a collector is the collection of irradiance $[15,16]$. For a collector, the irradiance $I_{C}$ is calculated as [17]

$I_{C}=I_{B C}+I_{D C}+I_{R C}$

Where $I_{B C}, I_{D C}$, and $I_{R C}$ denote the irradiance due to beam radiation, diffuse radiation, and reflected radiation respectively. These three irradiances due to different radiations are calculated as

$I_{B C}=I_{B} \times \cos \beta \cos \left(\phi_{S}-\phi_{C}\right) \sin \sum+\sin \beta \cos \sum$

Where $\beta, \phi_{S}, \phi_{C}$, and $\Sigma$ represents altitude angle, solar azimuth, collector azimuth, and collector tilt, respectively.

The value of $I_{B}$ can be calculated as

$I_{B}=A e^{-k m}$

Where $A$ is the apparent extracterrestrial flux which is defind as

$A=1160+75 \sin \left[\frac{360}{365}(n-275)\right]$

while $k$ is the optical depth with expression given in Eq (13).

$S=0.174+0.035 \sin \left[\frac{360}{365}(n-100)\right]$

Where $n$ is the number of the day in the year

The diffused radiation can be calculated as

$I_{D C}=I_{B} S\left(\frac{1+\cos \sum}{2}\right)$

Where $S$ is the sky diffuse factor which is calculated as

$S=0.95+0.04 \sin \left[\frac{360}{365}(n-100)\right]$

The reflected radiation for the fixed system is given as

$I_{R C, F}=I_{B} \rho(S+\sin \beta)\left(\frac{1-\cos \sum}{2}\right)$

\section{PNS system}

For the Polar axis North-South (PNS) system, the different radiations are calculated with declination angle $\delta$ as

$I_{B C}=I_{B} \times \cos \delta$

$I_{R C}=I_{B} S\left[\frac{1-\sin (\beta-\delta)}{2}\right]$

$I_{R C, N P S}=I_{B} \delta(S+\sin \beta)\left[\frac{1-\sin (\beta-\delta)}{2}\right]$

From (7), (15) and (18), the insolation for new technology, $I_{R C, P}$ is given by (19).

$I_{R C, P}=I_{R C, F} \times L R+I_{R C, 1 \text {-axistracker }}$ 
(a)

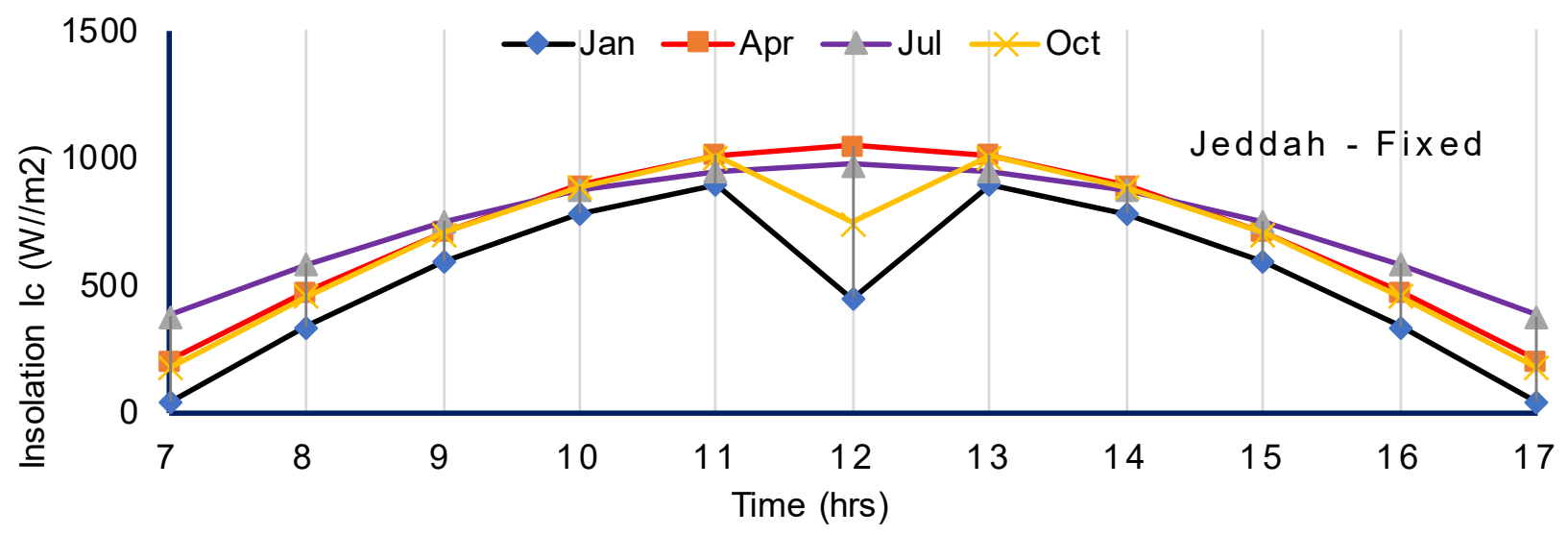

(b)

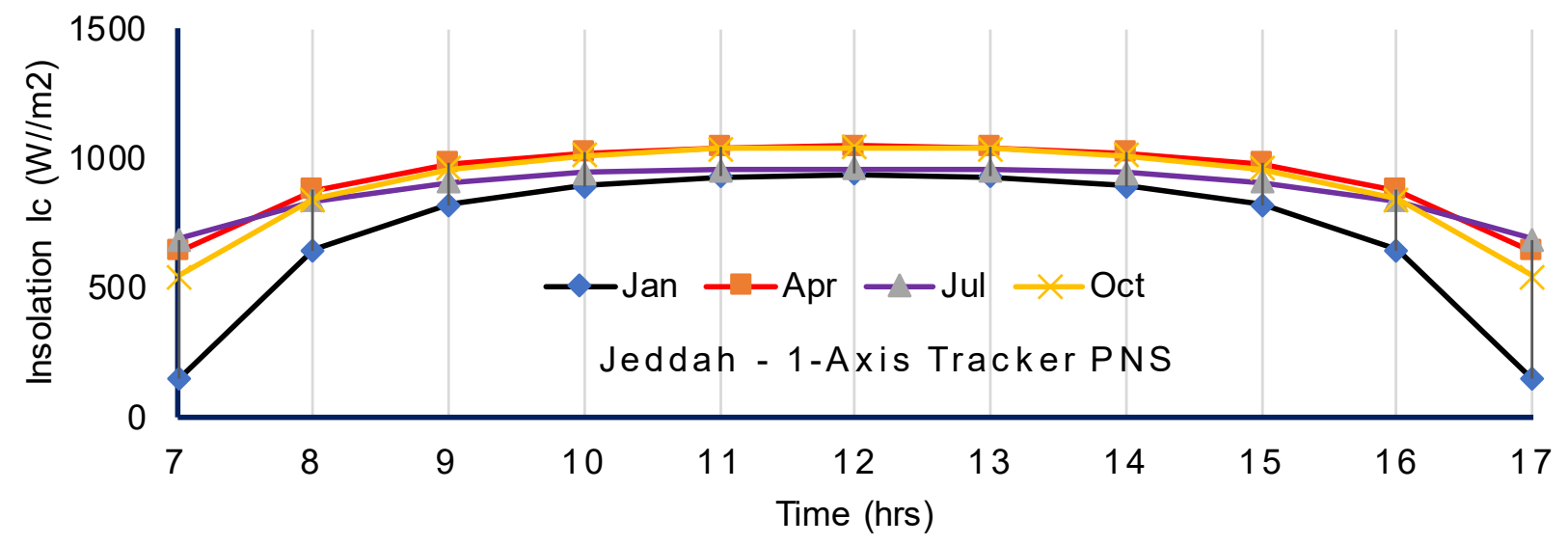

(c)

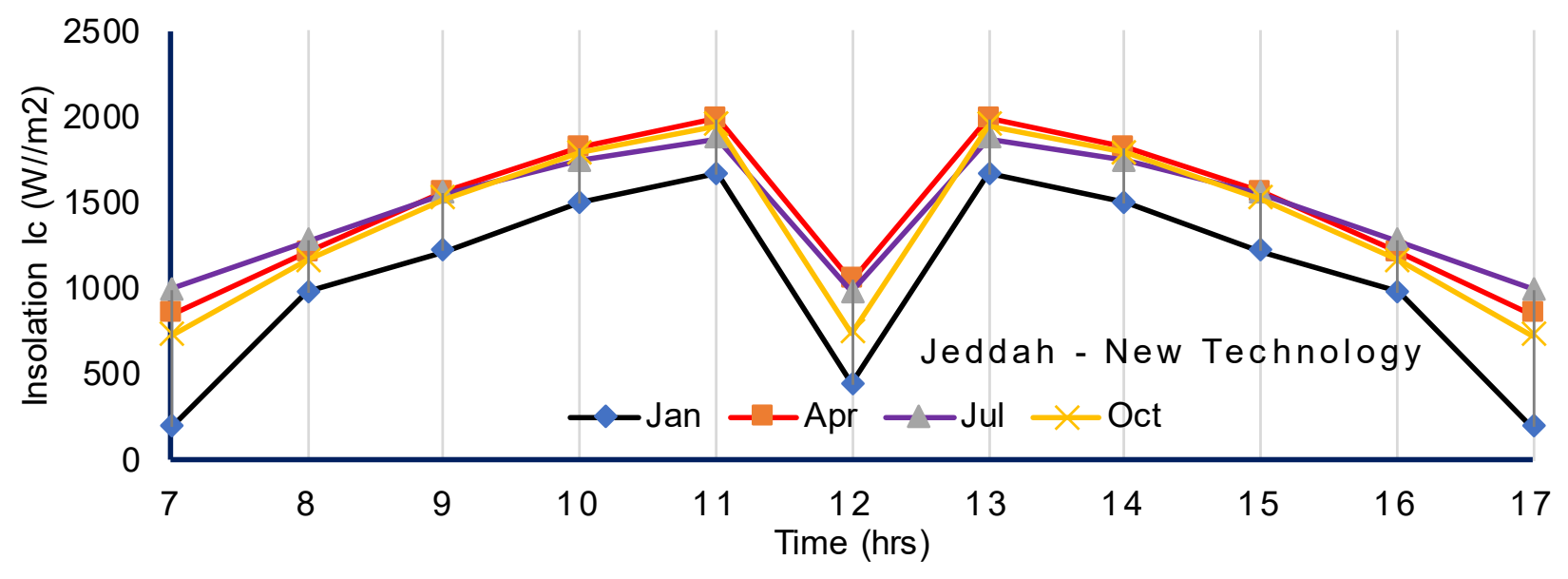

(d)

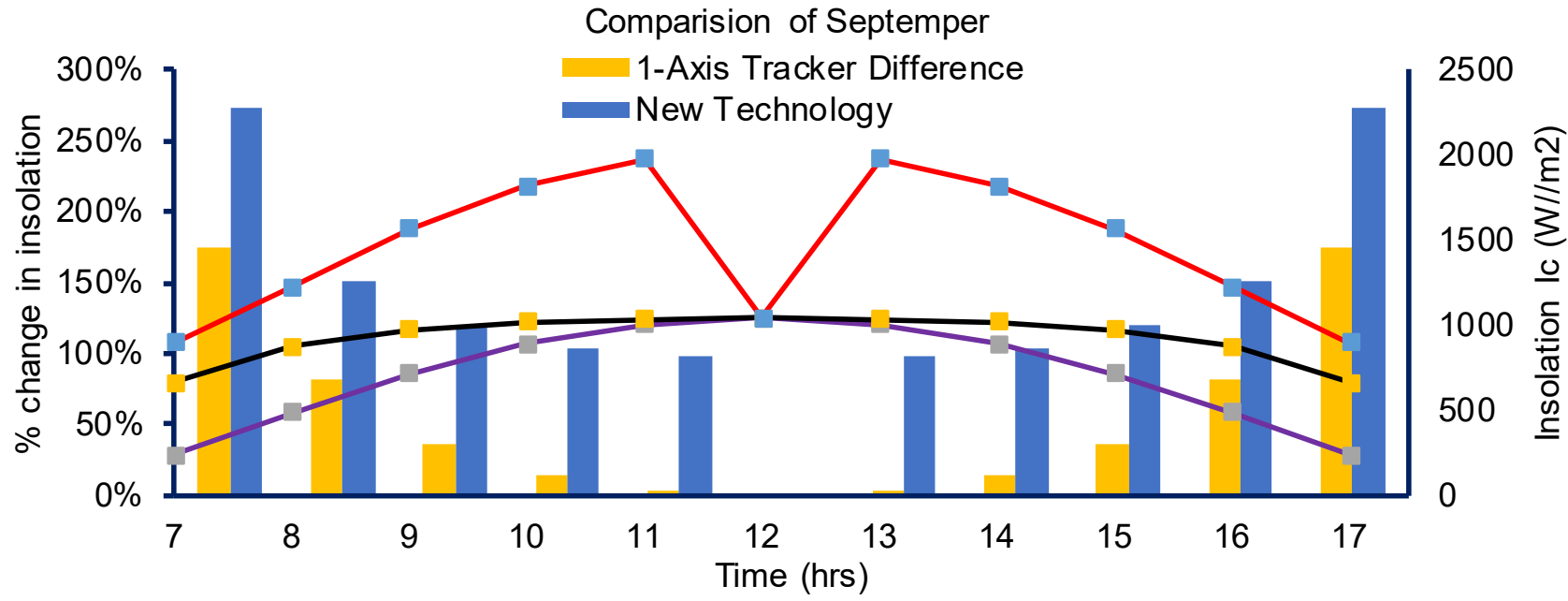

Figure 7: Insolation of (a) fixed system (b) NPS system, (c) new technology and (d) comparison of three different methods for September month 


\section{RESULTS AND DISUCSSION}

In order to show the improved performance of the proposed system, five different cities of Saudi Arabia have been considered [18-21]. These cities are Jeddah, Riyad, Dammam, Abha, and Tabouk. For Jeddah, the used paramentrs are: Latitude $=21.486^{\circ}$, Collector Azimuth $=0^{\circ}$, and Collector Tilt $=21.486^{\circ}$. For a fixed system, Fig. 7 (a) shows the variation of the insolation with respect to the time for the four different months for Jeddah. For the 1 st day of January at 7:00 hrs, the insolation has a smaller value, however, the value of insolation is about $400 \mathrm{~W} / \mathrm{m}^{2}$ for the 1st day of July at the same time. During the time period from 10:00 - 14:00, the level of insolation is about $800 \mathrm{~W} / \mathrm{m}^{2}$. After $14: 00 \mathrm{hrs}$, the insolation drops and at 17 $\mathrm{hrs}$, it reaches to a very low value. The peak insolation level with fixed system is achieved during the month of April and the isolation level is about $1000 \mathrm{~W} / \mathrm{m}^{2}$ at $12 \mathrm{hrs}$. Compare to the fixed system, the performance of the PNS system with a 1-axis tracker is much better. Fig. 7 (b) shows the variation of the insolation with respect to the time for four different months with the PNS system. With the PNS system, the variation of insolation is low

$$
\text { Riyad - Fixed }
$$

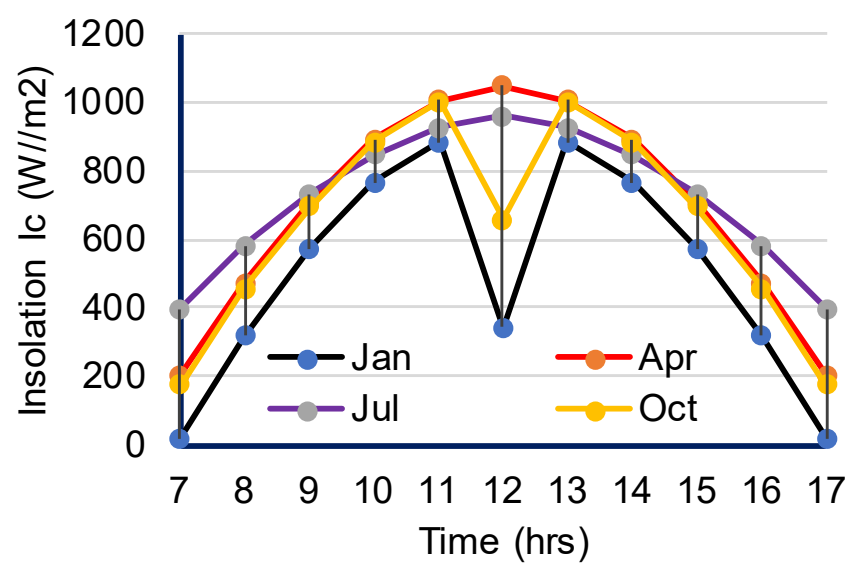

(a) and from 9:00 - 15:00 hrs, the insolation level is about $800 \mathrm{~W} / \mathrm{m}^{2}$. The peak insolation level with the PNS system is achieved during the month of April and October and the isolation is about $1000 \mathrm{~W} / \mathrm{m}^{2}$ at $12 \mathrm{hrs}$.

Fig. 7 (c) shows the changes in the insolation level with respect to the time for four different months with the proposed new technology. The insolation level of $1000 \mathrm{~W} / \mathrm{m}^{2}$ is achieved for the month of April, July, and October from 8:00 hrs to $16: 00 \mathrm{hrs}$. Further, the peak isolation level is about $2000 \mathrm{~W} / \mathrm{m}^{2}$ which is almost double compare to the other two cases. Also, the proposed new technology gives a higher value of insolation for the all-time duration for all four months compared to the fixed and PNS system. The comparison of different techniques for the month of September has been depicted in Fig. 7 (d). The proposed technology has a higher level of insolation compare to the other two methods of solar PV harvesting.

Similarly, Fig. 8-11 shows the performance of the three different technologies for solar harvesting for different cities of Saudi Arabia, and the proposed new technology gives improved performance in all cities for all months.

Riyad - 1-Axis Tracker PNS

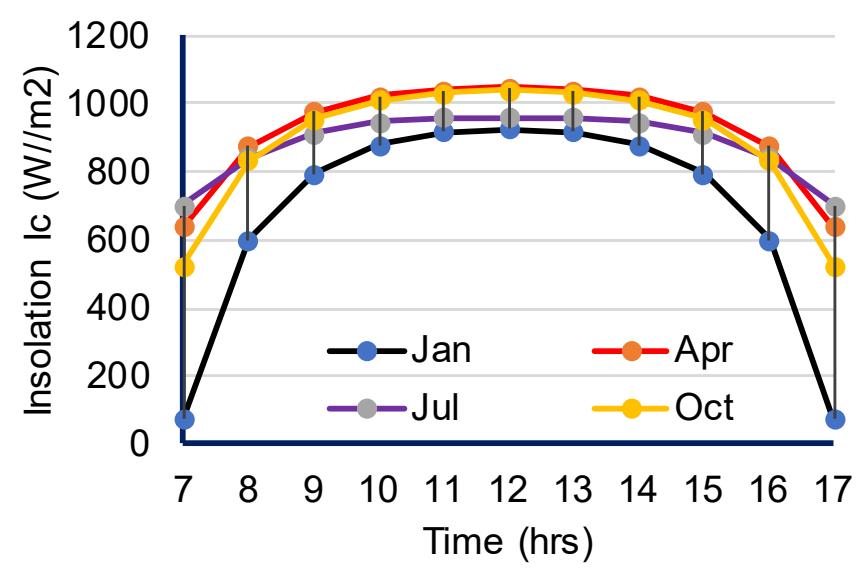

(b)

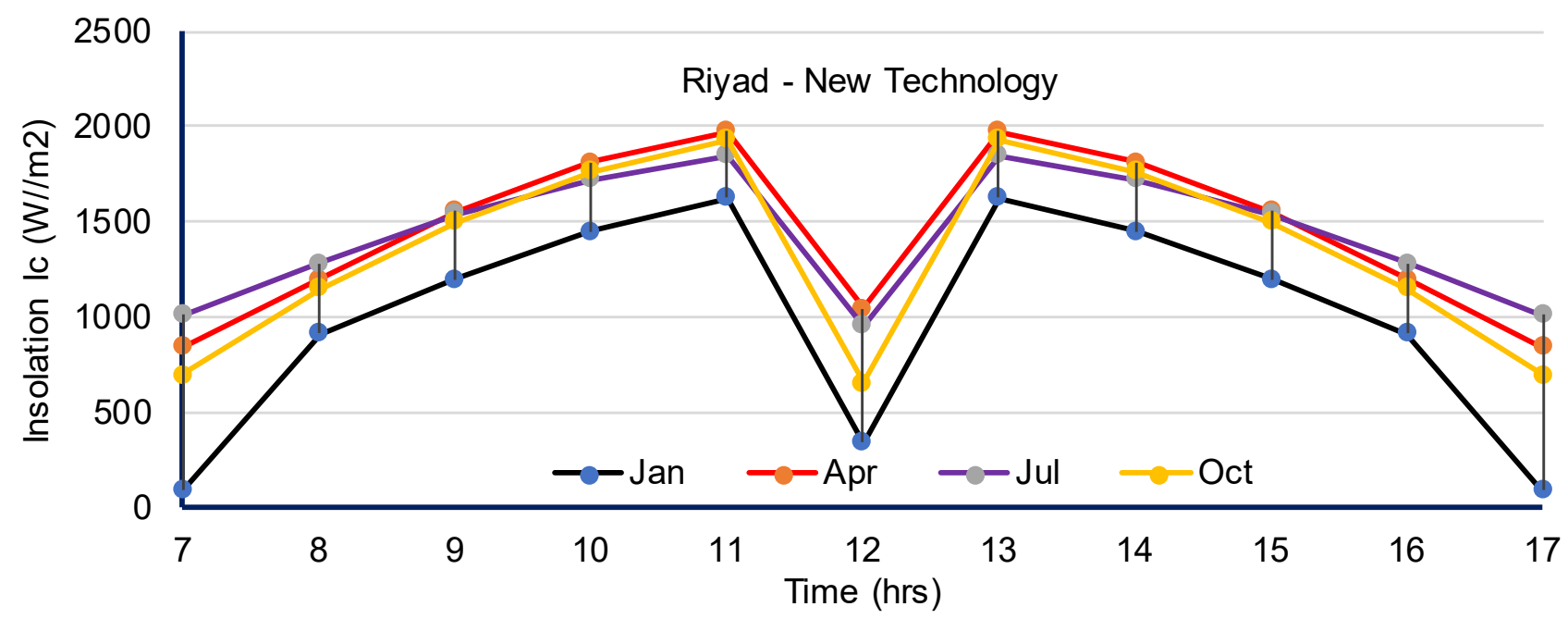

(c) 


\section{Comparision of Septemper}

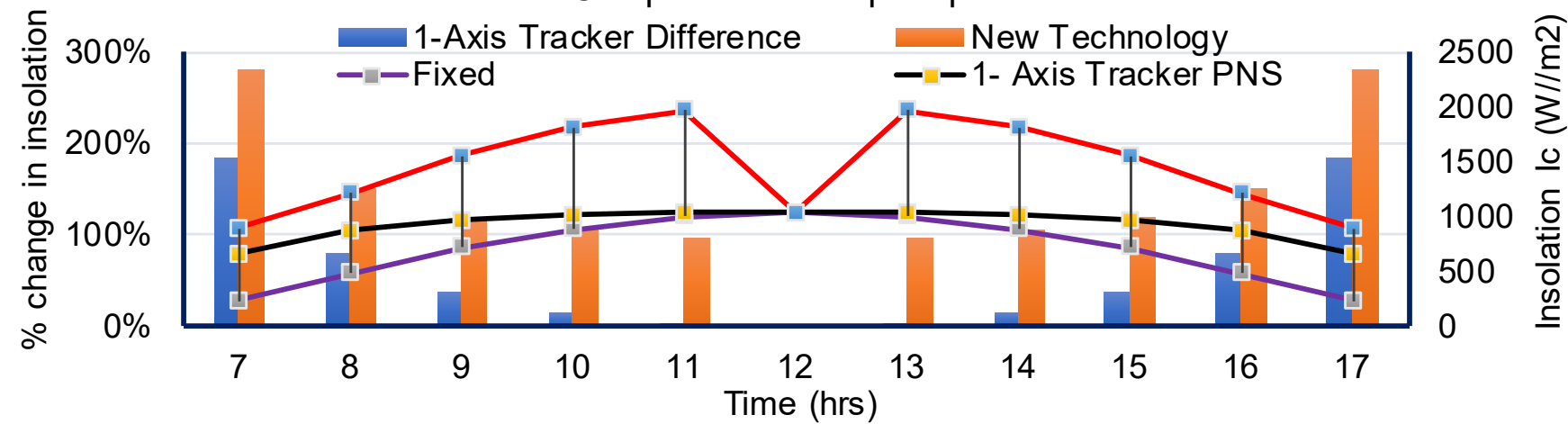

(d)

Figure 8: Insolation of (a) fixed system (b) NPS system, (c) new technology and (d) comparison of three different methods for September month

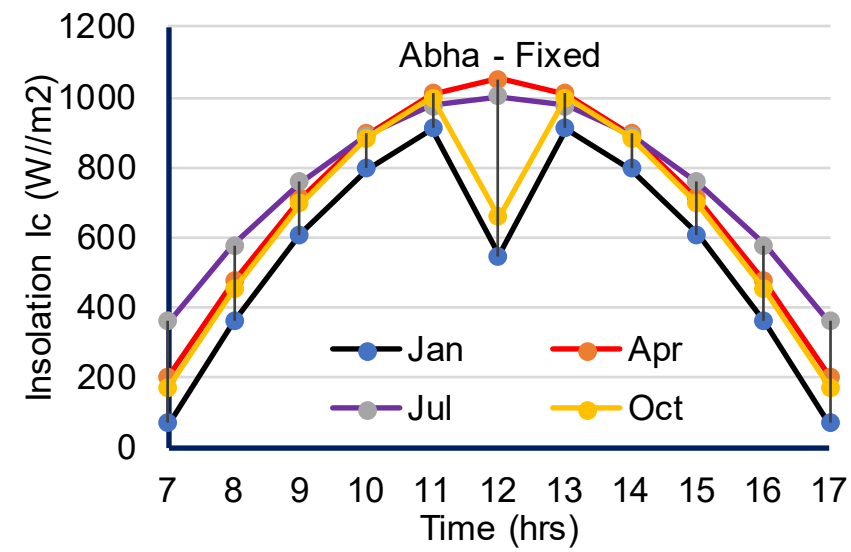

(a)

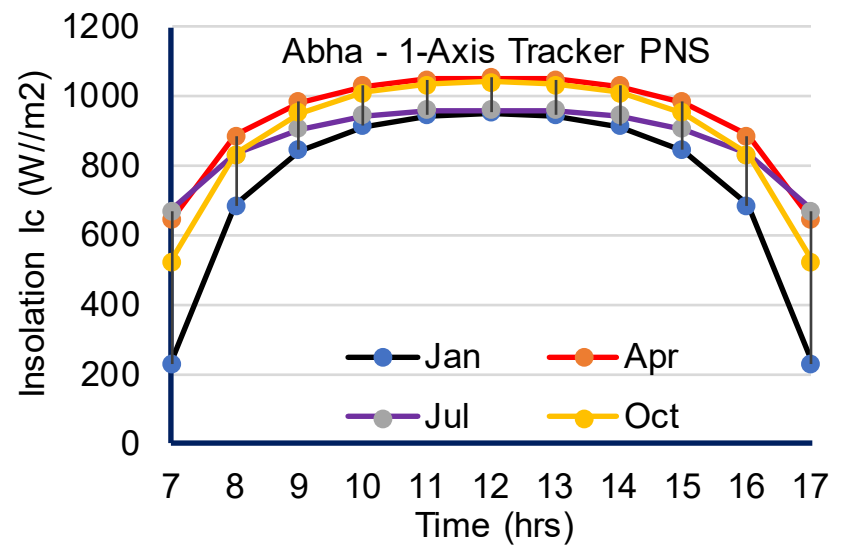

(b)

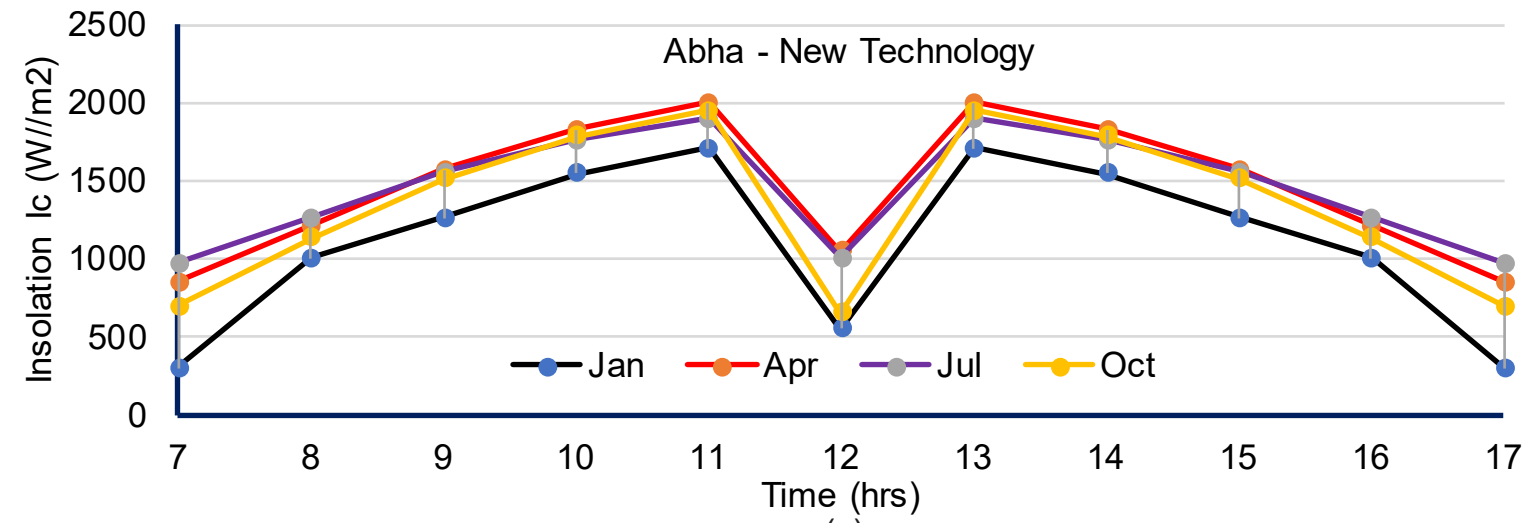

(c)

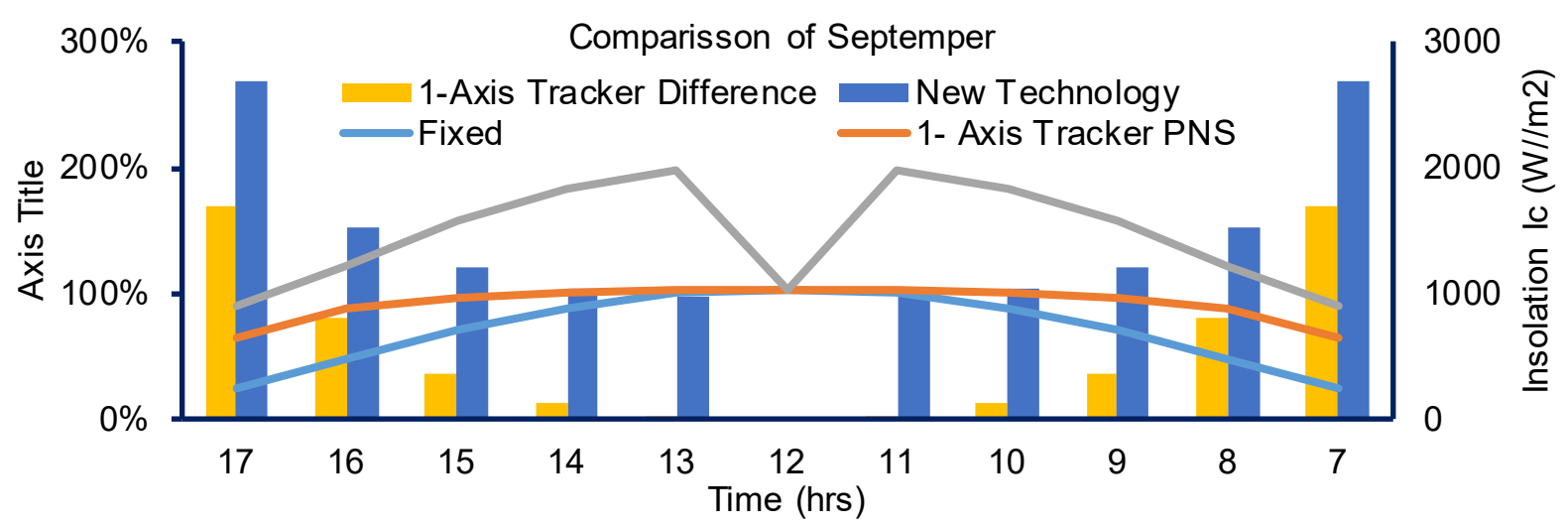

(d)

Figure 9: Insolation of (a) fixed system (b) NPS system, (c) new technology and (d) comparison of three different methods for September month 


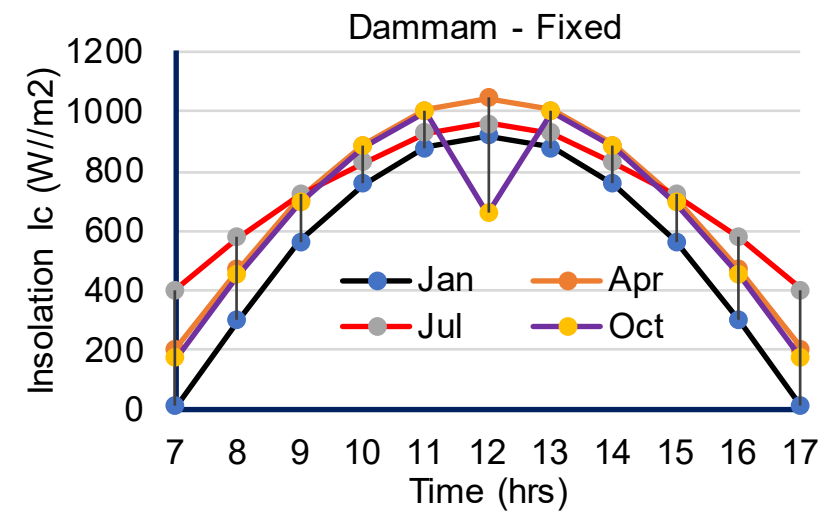

(a)

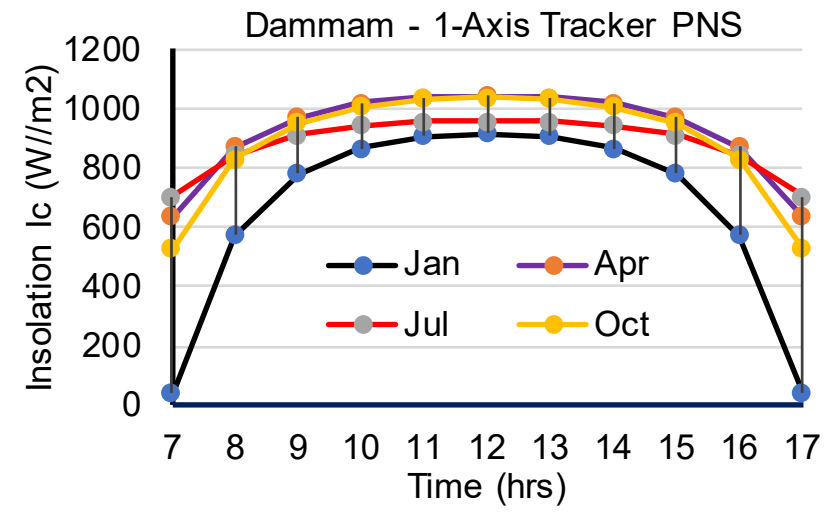

(b)

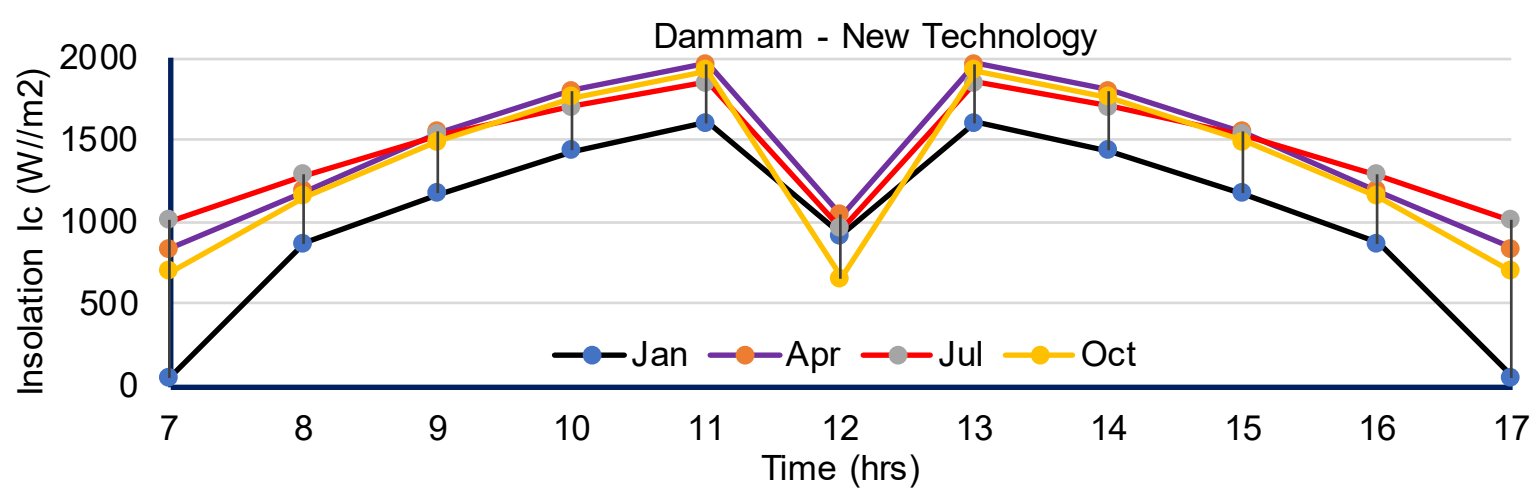

(c)

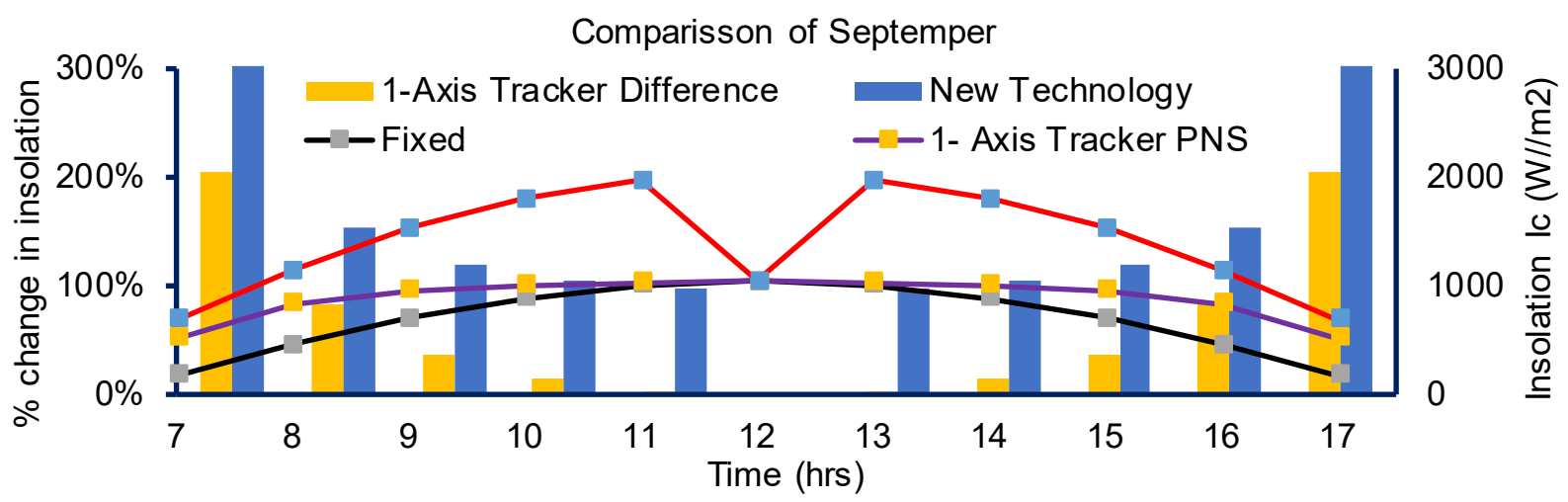

(d)

Figure 10: Insolation of (a) fixed system (b) NPS system, (c) new technology and (d) comparison of three different methods for September month

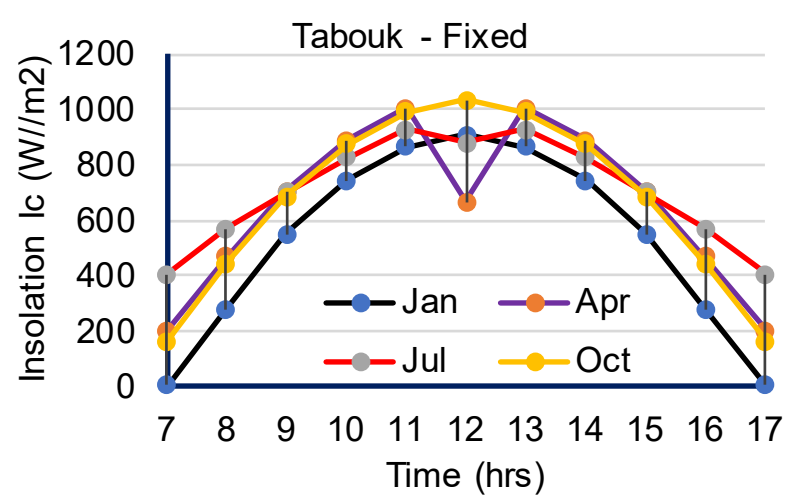

(a)

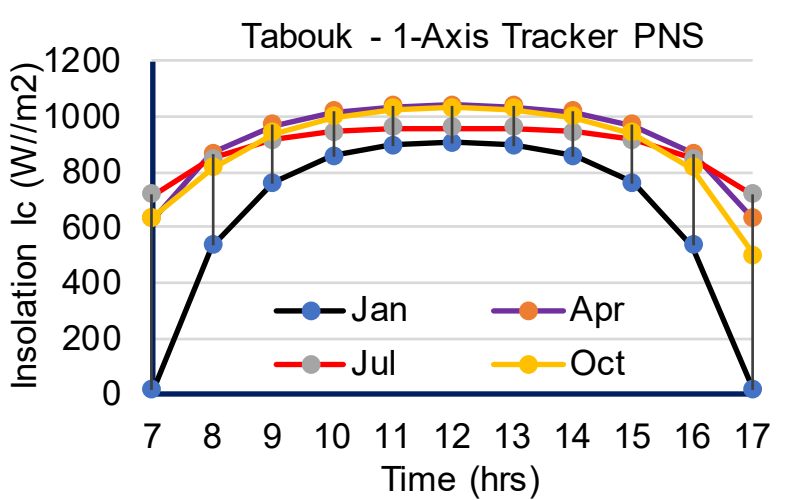

(b) 


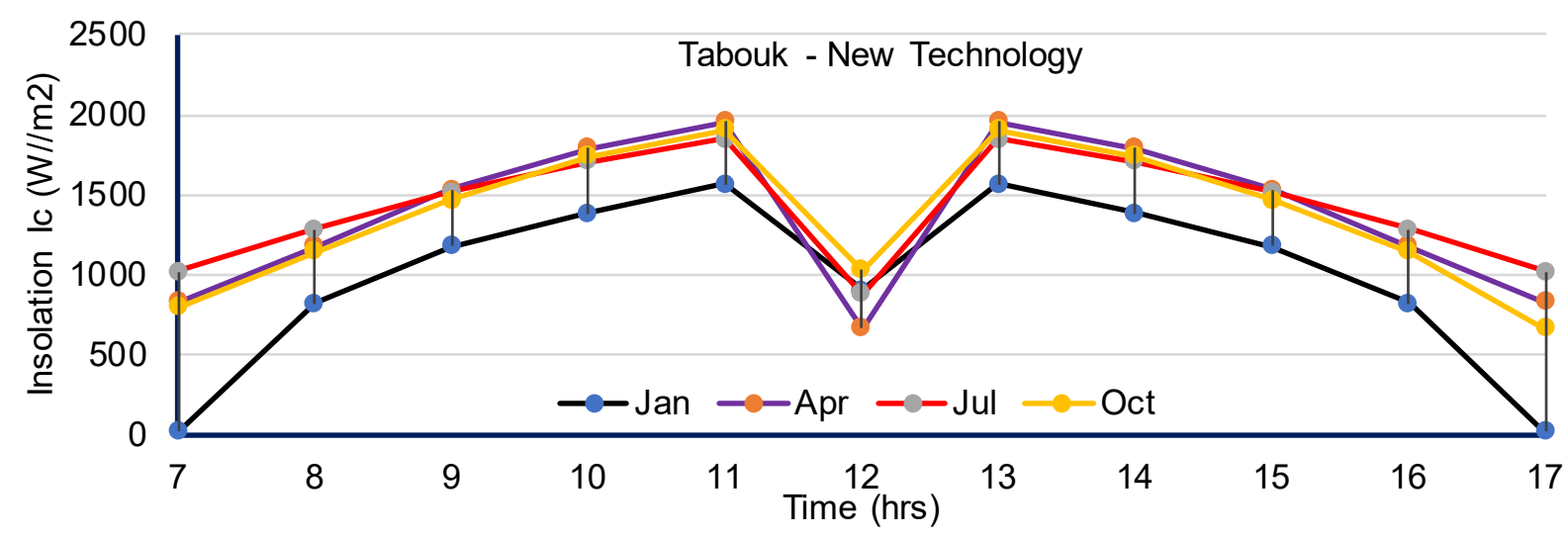

(c)

Comparisson of Septemper

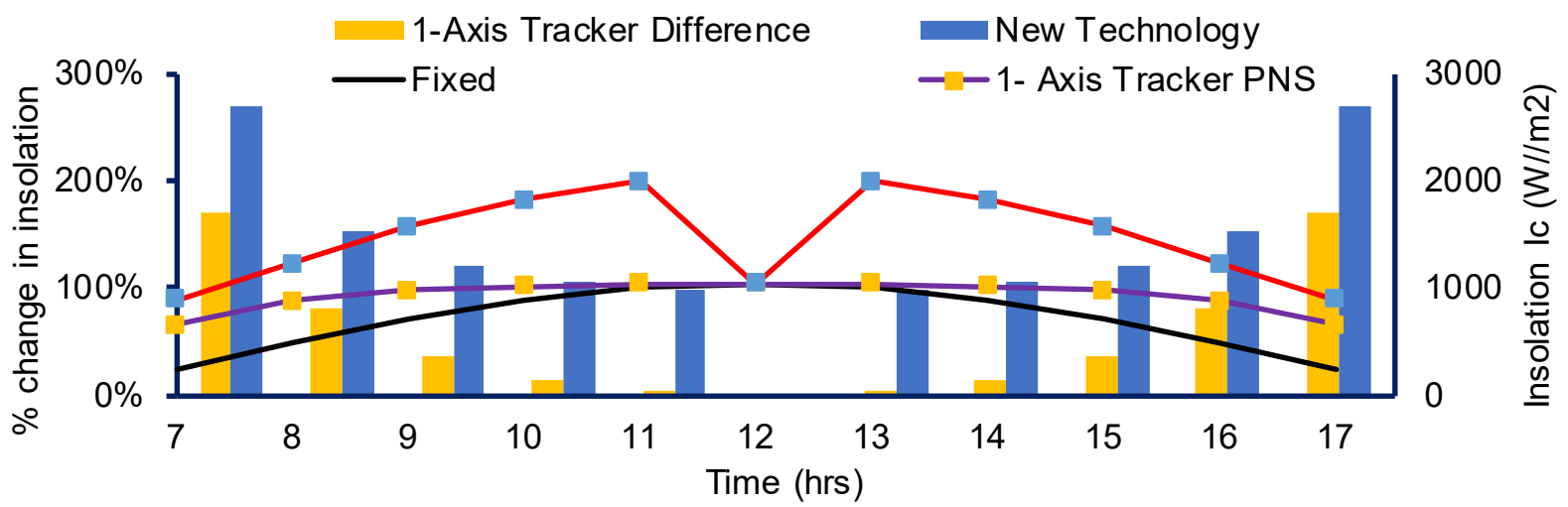

(d)

Figure 11: Insolation of (a) fixed system (b) NPS system, (c) new technology and (d) comparison of three different methods for September month

\section{CONCLUSION}

This paper proposed new technology for the solar photovoltaic harvesting method. In the proposed methods, the motor-operated adjustable mirrors are used for the improvement of the performance of the system. The performance of the proposed system has been validated through the theoretical analysis and the various comparison of the proposed system have been included in this paper which shows a better performance compare to the conventional systems. The major advantage of the proposed system has been observed in the collection of solar insolation which is two-fold compare to the conventional technique. However, during the of 11:00 to 13:00 $\mathrm{PM}$, the reduction in the collected isolation is observed, however this lower value of isolation is still higher than the conversion fixed method. Also, the time duration for a higher amount of collected insolation has been improved.

\section{REFERENCES}

1. Hu J, Chen W, Yang D, et al (2016) Energy performance of ETFE cushion roof integrated photovoltaic/thermal system on hot and cold days. Appl Energy 173:40-51. https://doi.org/10.1016/j.apenergy.2016.03.111
2. Yau YH, Lim KS (2016) Energy analysis of green office buildings in the tropics - Photovoltaic system. Energy Build 126:177-193. https://doi.org/10.1016/j. enbuild.2016.05.010

3. Wang Y, Zhou S, Huo H (2014) Cost and CO2 reductions of solar photovoltaic power generation in China: Perspectives for 2020. Renew. Sustain. Energy Rev. 39:370-380

4. Parida B, Iniyan S, Goic R (2011) A review of solar photovoltaic technologies. Renew. Sustain. Energy Rev. 15:1625-1636

5. da Silva RM, Fernandes JLM (2010) Hybrid photovoltaic/thermal $(\mathrm{PV} / \mathrm{T})$ solar systems simulation with Simulink/Matlab. Sol Energy 84:1985-1996. https:// doi.org/10.1016/j.solener.2010.10.004

6. Elbreki AM, Alghoul MA, Al-Shamani AN, et al (2016) The role of climatic-design-operational parameters on combined $\mathrm{PV} / \mathrm{T}$ collector performance: A critical review. Renew. Sustain. Energy Rev. 57:602-647

7. Prince Winston D, Kumaravel S, Praveen Kumar B, Devakirubakaran S (2020) Performance improvement of solar PV array topologies during various partial shading conditions. Sol Energy 196:228-242. https://doi.org/10.1016/j.solener.2019.12.007 
8. Peng Z, Herfatmanesh MR, Liu Y (2017) Cooled solar PV panels for output energy efficiency optimisation. Energy Convers Manag 150:949-955. https:// doi.org/10.1016/j.enconman.2017.07.007

9. Shaik R, Beemkumar N, Adharsha H, et al (2019) Efficiency enhancement in a PV operated solar pump by effective design of VFD and tracking system. In: Materials Today: Proceedings. Elsevier Ltd, pp 454462

10. Royne A, Dey CJ, Mills DR (2005) Cooling of photovoltaic cells under concentrated illumination: A critical review. Sol Energy Mater Sol Cells 86:451-483. https://doi.org/10.1016/j.solmat.2004.09.003

11. Khan M, Ko B, Alois Nyari E, et al (2017) Performance Evaluation of Photovoltaic Solar System with Different Cooling Methods and a Bi-Reflector PV System (BRPVS): An Experimental Study and Comparative Analysis. Energies 10:826. https://doi.org/10.3390/ en10060826

12. Potnuru SR, Pattabiraman D, Ganesan SI, Chilakapati N (2015) Positioning of PV panels for reduction in line losses and mismatch losses in PV array. Renew Energy 78:264-275. https://doi.org/10.1016/j. renene.2014.12.055

13. Sahay A, Sethi VK, Tiwari AC, Pandey M (2015) A review of solar photovoltaic panel cooling systems with special reference to Ground coupled central panel cooling system (GC-CPCS). Renew. Sustain. Energy Rev. 42:306-312

14. Bassi H (2020) Method for harvesting solar energy. US Patent, US10804838B2.
15. El-Sebaii AA, Al-Hazmi FS, Al-Ghamdi AA, Yaghmour SJ (2010) Global, direct and diffuse solar radiation on horizontal and tilted surfaces in Jeddah, Saudi Arabia. Appl Energy 87:568-576. https://doi.org/10.1016/j. apenergy.2009.06.032

16. Hay JE (1979) Calculation of monthly mean solar radiation for horizontal and inclined surfaces. Sol Energy 23:301-307. https://doi.org/10.1016/0038092X(79)90123-3

17. Spencer JW (1972) Computer estimation of direct solar radiation on clear days. Sol Energy 13:437-438. https://doi.org/10.1016/0038-092X(72)90011-4

18. Alrashoud K, Tokimatsu K (2020) An exploratory study of the public's views on residential solar photovoltaic systems in oil-rich Saudi Arabia. Environ Dev 35:100526. https://doi.org/10.1016/j.envdev.2020.100526

19. Rashwan SS, Shaaban AM, Al-Suliman F (2017) A comparative study of a small-scale solar PV power plant in Saudi Arabia. Renew. Sustain. Energy Rev. 80:313-318

20. Al Garni HZ, Awasthi A, Wright D (2019) Optimal orientation angles for maximizing energy yield for solar PV in Saudi Arabia. Renew Energy 133:538-550. https://doi.org/10.1016/j.renene.2018.10.048

21. Elshurafa AM, Alsubaie AM, Alabduljabbar AA, Al-Hsaien SA (2019) Solar PV on mosque rooftops: Results from a pilot study in Saudi Arabia. J Build Eng 25:100809. https://doi.org/10.1016/j. jobe.2019.100809 